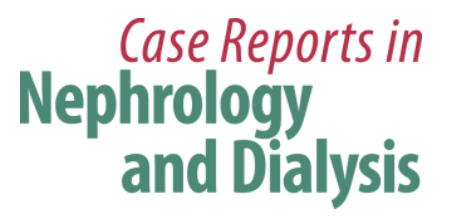

\title{
A Case of Acute Kidney Injury in a Patient with Renal Hypouricemia without Intense Exercise
}

\author{
Daiki Aomura Kosuke Sonoda Makoto Harada Koji Hashimoto \\ Yuji Kamijo \\ Department of Nephrology, Shinshu University School of Medicine, Matsumoto, Japan
}

\section{Keywords}

Exercise-induced acute kidney injury · Renal hypouricemia $\cdot$ Vasopressor

\begin{abstract}
Exercise-induced acute kidney injury (EIAKI) frequently develops in patients with renal hypouricemia (RHUC). However, several cases of RHUC with acute kidney injury (AKI) but without intense exercise have been reported. We encountered a 15-year-old male with RHUC who experienced AKI. He reported no episodes of intense exercise and displayed no other representative risk factors of EIAKI, although a vasopressor had been administered for orthostatic dysregulation before AKI onset. His kidney dysfunction improved with discontinuation of the vasopressor and conservative treatment. Thus, AKI can develop in patients with RHUC in the absence of intense exercise, for which vasopressors may be a risk factor.
\end{abstract}

(C) 2020 The Author(s)

Published by S. Karger AG, Basel 


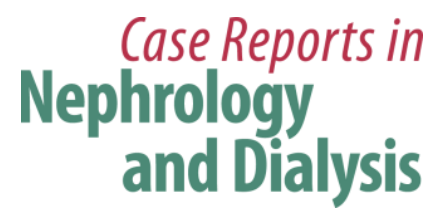

Case Rep Nephrol Dial 2020;10:26-34

DOI: 10.1159/000506673

(C) 2020 The Author(s). Published by S. Karger AG, Basel www.karger.com/cnd

Aomura et al.: A Case of Acute Kidney Injury in a Patient with Renal Hypouricemia without Intense Exercise

\section{Introduction}

Exercise-induced acute kidney injury (EIAKI) is a major complication in patients with renal hypouricemia (RHUC). EIAKI usually develops after intense exercise, such as anaerobic exertion, and is not accompanied by rhabdomyolysis [1]. However, there are several case reports of patients experiencing EIAKI without intense exercise [2-4]. Although the pathomechanism and risk factors of EIAKI remain unclear, many reports suggest that an oxidation-reduction imbalance is associated with EIAKI onset [5]. We herein report a case of acute kidney injury (AKI) in a patient with RHUC in the absence of intense exercise, which may have been caused by an oral vasopressor.

\section{Case Report}

A 15-year-old male complained of strong fatigue after intense exercise since childhood. He had no remarkable medical history apart from allergic rhinitis. After entering high school, he often felt unwell, especially in the morning, and frequently missed classes. He was diagnosed as having orthostatic dysregulation and prescribed amezinium metilsulfate $10 \mathrm{mg} /$ day, but his symptoms persisted. Eight days after the start of treatment he was switched to etilefrine $5 \mathrm{mg}$ /day. However, his fatigue progressively worsened. He was found vomiting and unresponsive after collapsing in the bathroom on the eighth night following the prescription change and taken to the hospital by his family. In the emergency room he exhibited mild consciousness disturbance (Glasgow Coma Scale: E4V4M6) and complained of right lower abdominal pain. Laboratory tests (blood and urine), whole-body computed tomography, and head magnetic resonance imaging did not indicate any abnormalities (serum creatinine level $1.0 \mathrm{mg} / \mathrm{dL}$, uric acid level $7.2 \mathrm{mg} / \mathrm{dL}$ ). His conscious state and abdominal pain were improved on the next day, but his blood pressure gradually increased from 100/60 to 180/80 mm Hg and his serum creatinine level rose from 1.0 to $5.5 \mathrm{mg} / \mathrm{dL}$ during 5 days of admission. He was then transferred to our institution for the treatment of AKI and severe hypertension.

At the time of admission to our hospital the patient was fully conscious and alert. His body temperature was $37.2^{\circ} \mathrm{C}$, blood pressure was $161 / 98 \mathrm{~mm} \mathrm{Hg}$, heart rate was $83 \mathrm{beats} / \mathrm{min}$, and respiratory rate was 17 breaths/min. His height was $174 \mathrm{~cm}$ and his body weight was $54 \mathrm{~kg}$. Physical examination detected no signs of dehydration, rash, or other abnormalities of the neck, chest, abdomen, or extremities. He had been taking loratadine $10 \mathrm{mg} /$ day for his allergic rhinitis for several months. Both loratadine and etilefrine had been discontinued upon admission to the previous hospital. There was no family history of kidney dysfunction, and he reported no episodes of intense exercise other than daily commuting by bicycle to school. No alcohol consumption, smoking, or illegal drug use were reported. His laboratory data at the time of transfer to our hospital are summarized in Table 1. Urinalysis showed mild proteinuria $(0.66 \mathrm{~g} / \mathrm{gCr})$ and elevation of the tubulointerstitial injury marker $\beta 2$ microglobulin $(1,498 \mu \mathrm{g} / \mathrm{L})$. Hematuria was not observed. His serum level of uric acid was low at $3.2 \mathrm{mg} / \mathrm{dL}$ and his fractional excretion of uric acid was high at $49.7 \%$. Laboratory markers of rhabdomyolysis, diabetes mellitus, infection, and collagen diseases such as creatine phosphokinase, hemoglobin A1c, C-reactive protein, and autoimmune antibodies were all within normal range. An electrocardiogram disclosed left anterior hemiblock and nonspecific intraventricular con- 


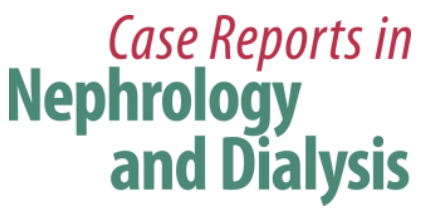

\begin{tabular}{l|l} 
Case Rep Nephrol Dial 2020;10:26-34 \\
\hline DOI: 10.1159/000506673 & $\begin{array}{l}\text { ( 2 2020 The Author(s). Published by S. Karger AG, Basel } \\
\text { www.karger.com/cnd }\end{array}$
\end{tabular}

Aomura et al.: A Case of Acute Kidney Injury in a Patient with Renal Hypouricemia without Intense Exercise

duction delay that had been detected when he was an elementary school student. A chest Xray revealed no abnormalities. Ultrasound echography showed bilateral mild kidney swelling with increased renal cortical echogenicity (Fig. 1). No stenotic lesions were detected in the aorta or renal arteries, although the resistance index of the intrarenal arteries was slightly high (left 0.69 , right 0.69 ), indicating a circulatory disturbance in the renal microvessels. Hydronephrosis and renal calcification were absent. An ultrasound-guided kidney biopsy performed 3 days after arrival at our hospital showed mild interstitial edema, vascular endothelial cell swelling in the renal interlobular arterioles, and no obvious signs of acute tubular necrosis (ATN) (Fig. 2). Treatment with continuous intravenous infusion of extracellular fluids and nicardipine gradually improved his kidney function and hypertension. His serum uric acid level decreased to $1.0 \mathrm{mg} / \mathrm{dL}$ (Fig. 3), and his fractional excretion of uric acid was at $55.9 \%$ at 10 days after admission. He was ultimately diagnosed as having AKI with RHUC and discharged 12 days after transfer to our hospital. Hypouricemia was found in his parents and a sister, indicating a hereditary condition. However, genetic screening did not detect any known causative RHUC mutations on URAT1/SLC22A12 or GLUT9/SLC2A9.

\section{Discussion}

Ishikawa et al. [6] first described EIAKI as AKI with accompanying abdominal or lower back pain after intense exercise, such as a 100-meter dash. EIAKI is differentiated from AKI with rhabdomyolysis by normal or slightly elevated serum myoglobin and creatine phosphokinase levels. EIAKI typically occurs in young males, with more than half having RHUC. Enhanced computed tomography often displays a wedge-shaped contrast defect in the kidneys. As for the clinical course of EIAKI, kidney dysfunction improves naturally without any special treatment $[1,7]$. Although the reported patient had no intense episodes of exercise, EIAKI was diagnosed because he had RHUC, his kidney function recovered naturally, and he was young and male.

Blood pressure and serum creatinine level in our patient increased gradually following admission to the former hospital. As high blood pressure alone might cause AKI, we could not exclude the possible involvement of hypertension in AKI development. However, his serum creatinine level ultimately improved to $0.7 \mathrm{mg} / \mathrm{dL}$ after the final discharge despite having been $1.0 \mathrm{mg} / \mathrm{dL}$ on first admission, indicating that it had already been elevated by $0.3 \mathrm{mg} / \mathrm{dL}$ at the former hospital. Considering the fact that his blood pressure was normal on admission, AKI was thought to have developed before blood pressure elevation. Furthermore, his serum uric acid level was much higher on first admission $(7.2 \mathrm{mg} / \mathrm{dL})$ than at discharge $(1.0 \mathrm{mg} / \mathrm{dL})$, suggesting AKI onset prior to the former hospital visit. We suspected that AKI caused hypertension, which in turn worsened AKI. The elevation of blood pressure was assumed to be an exacerbation factor of EIAKI rather than its main cause.

The reported patient had no intense episodes of exercise. Lee et al. [3] described 17 AKI patients with abdominal or lower back pain who exhibited the characteristic patchy kidney sign on enhanced computed tomography. Among them, 5 patients reported no episodes of intense exercise. To the best of our knowledge, there have been 8 patients with EIAKI who did not have any episodes of intense exertion [2-4], with 5 experiencing infection or analgesic usage before EIAKI onset (Table 2), thought to be risk factors of EIAKI in addition to RHUC [3, 


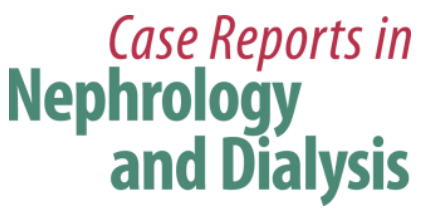

\begin{tabular}{l|l} 
Case Rep Nephrol Dial 2020;10:26-34 \\
\hline DOI: 10.1159/000506673 & $\begin{array}{l}\text { @ } 2020 \text { The Author(s). Published by S. Karger AG, Basel } \\
\text { www.karger.com/cnd }\end{array}$
\end{tabular}

Aomura et al.: A Case of Acute Kidney Injury in a Patient with Renal Hypouricemia without Intense Exercise

8, 9]. These reports support the notion that EIAKI can develop without intense exercise and the existence of risk factors other than strong exertion. However, to date no reports have focused on the relationship between lack of intense exercise and the etiology and development mechanism of EIAKI.

The pathomechanism of EIAKI is unclear, but renal circulatory disturbance by reactive oxygen species (ROS) is thought to be a main cause [5]. Intense exercise, such as anaerobic exertion, produces large amounts of ROS, which are rapidly removed by uric acid and other scavengers in the healthy population [8]. Patients with RHUC have insufficient scavengers, resulting in inadequate ROS removal and the subsequent activation of vasoconstrictive factors, vasoconstriction, and renal ischemia [2]. Since renal vasoconstriction is known to trigger further vasoconstriction and oxidative stress via activation of the renin-angiotensin system and blood pressure elevation [10], EIAKI patients are thought to show a vicious cycle between oxidative stress and vasoconstriction - oxidative stress causes stronger vasoconstriction and vasoconstriction causes more oxidative stress - culminating in acute and severe renal injury. In the present case, the patient had been taking vasopressors for orthostatic dysregulation for 15 days prior to the onset of AKI. Amezinium metilsulfate inhibits monoamine oxidase activity and suppresses the uptake of noradrenaline, while etilefrine activates type $\alpha 1$ and $\beta 1$ adrenaline receptors. Thus, both vasopressors increased cardiac output and the constriction of peripheral vessels [11,12]. Bellomo et al. [13] reported that activation of type $\alpha 1$ adrenaline receptors could cause excessive renal vasoconstriction and decreased renal blood flow in models of healthy renal hemodynamics. Radaković et al. [14] described that adrenaline induction increased ROS and caused a disruption in oxidant/antioxidant balance. Considering these results and the developmental mechanism of EIAKI (i.e., ROS and renal ischemia), we suspect that the vasopressors may have affected the onset or worsening of EIAKI by increasing ROS, exacerbating vasoconstriction, and forming a vicious cycle of diminished renal hemodynamics. Karasawa et al. [15] reported a case of EIAKI who was given midodrine, another vasopressor, before the onset of EIAKI, and Saito et al. [16] described that vasoexpansion by low-dose dopamine improved the resistance index of renal arterioles in 2 cases of EIAKI, implying the relation between vasopressors and EIAKI in clinical settings. Although no studies have directly addressed the relationship between vasopressors and EIAKI, past reports and our own results indicate an importance of catecholamine level homeostasis in the pathogenesis of EIAKI. We suspect that vasopressors may be associated with AKI onset in RHUC patients and may be a risk factor of EIAKI.

Renal biopsy showed no significant abnormalities in the present case. Although patients with EIAKI generally exhibit ATN, Ohta et al. [2] reported no abnormalities in 6 of 28 renal biopsies from EIAKI patients, which implied that EIAKI could develop without ATN. AKI with renal ischemia often causes ATN. However, tubular necrosis is sometimes absent without a sufficient degree or duration of ischemia, and early treatment for renal ischemia leads to a rapid improvement in renal function in such cases [17]. In the present patient, vasopressors, which might be a risk factor for EIAKI, were discontinued and intravenous antihypertensive medication was induced just after the first admission. The serum uric acid level was temporarily elevated on admission by AKI, and the patient's scavenging ability with serum uric acid was thought to be temporarily improved. These factors could have mitigated the vicious cycle between renal vasoconstriction and oxidative stress, reduced the severity of renal ischemia, 

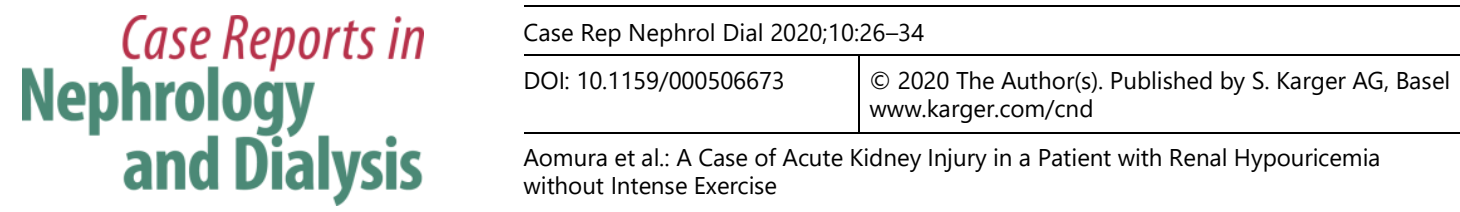

Aomura et al.: A Case of Acute Kidney Injury in a Patient with Renal Hypouricemia without Intense Exercise

and prevented ATN development. However, as no studies have addressed the cause or meaning of a lack of ATN in some EIAKI patients, a greater number of studies are needed.

In conclusion, AKI can develop in patients with RHUC without intense exercise, possibly through the use of vasopressors. Further related case reports are needed to clarify the association between vasopressor use and AKI in patients with RHUC.

\section{Statement of Ethics}

The present case report adhered to the Declaration of Helsinki. Informed consent for publication was obtained from the patient.

\section{Disclosure Statement}

The authors declare no conflicts of interest.

\section{Funding Sources}

The authors received no specific funding for this work.

\section{Author Contributions}

D. Aomura drafted the article. K. Sonoda, M. Harada, and K. Hashimoto revised the article critically for important intellectual content. Y. Kamijo revised the article critically for important intellectual content and gave final approval of the version to be submitted.

\section{References}

1 Ishikawa I. Exercise-induced acute renal failure - acute renal failure with severe loin pain and patchy renal ischemia after anaerobic exercise. Tokyo: Springer; 2007.

2 Ohta T, Sakano T, Igarashi T, Itami N, Ogawa T; ARF Associated with Renal Hypouricemia Research Group. Exercise-induced acute renal failure associated with renal hypouricaemia: results of a questionnaire-based survey in Japan. Nephrol Dial Transplant. 2004 Jun;19(6):1447-53.

3 Lee J, Lee SW, Lee JW, Chin HJ, Joo KW, Kim YS, et al. Clinical characteristics of acute renal failure with severe loin pain and patchy renal vasoconstriction. Kidney Res Clin Pract. 2012 Sep;31(3):170-6.

4 Sugimoto T, Ide R, Uzu T, Kashiwagi A. Recurring exercise-induced acute renal failure with usual daily work. Nephrology (Carlton). 2007 Feb;12(1):110.

5 Murakami T, Kawakami H, Fukuda M, Furukawa S. Patients with renal hypouricemia are prone to develop acute renal failure - why? Clin Nephrol. 1995 Mar;43(3):207-8.

6 Ishikawa I, Saito Y, Shinoda A, Onouchi Z. Evidence for patchy renal vasoconstriction in man: observation by CT scan. Nephron. 1981;27(1):31-4.

7 Ishikawa I. Acute renal failure with severe loin pain and patchy renal ischemia after anaerobic exercise in patients with or without renal hypouricemia. Nephron. 2002 Aug;91(4):559-70. 


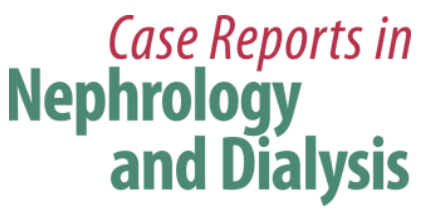

\begin{tabular}{l|l}
\hline Case Rep Nephrol Dial 2020;10:26-34 \\
\hline DOI: 10.1159/000506673 & $\begin{array}{l}\text { (c) } 2020 \text { The Author(s). Published by S. Karger AG, Basel } \\
\text { www.karger.com/cnd }\end{array}$
\end{tabular}

Aomura et al.: A Case of Acute Kidney Injury in a Patient with Renal Hypouricemia without Intense Exercise

8 Ames BN, Cathcart R, Schwiers E, Hochstein P. Uric acid provides an antioxidant defense in humans against oxidant- and radical-caused aging and cancer: a hypothesis. Proc Natl Acad Sci USA. 1981 Nov;78(11):685862.

9 Watanabe T. Patchy renal vasoconstriction after exercise in a child without renal hypouricemia. Pediatr Nephrol. 2002 Apr;17(4):284-6.

10 Araujo M, Wilcox CS. Oxidative stress in hypertension: role of the kidney. Antioxid Redox Signal. 2014 Jan; 20(1):74-101.

11 Lenke D, Gries J, Kretzschmar R. Pharmacology of amezinium, a novel antihypotensive drug. III. Studies on the mechanism of action. Arzneimittelforschung. 1981;31(9a):1558-65.

12 Offermeier J, Dreyer AC. A comparison of the effects of noradrenaline, adrenaline and some phenylephrine derivatives on alpha-, beta- and beta-adrenergic receptors. S Afr Med J. 1971 Mar;45(10):265-7.

13 Bellomo R, Kellum JA, Wisniewski SR, Pinsky MR, Ondulik B. Effects of norepinephrine on the renal vasculature in normal and endotoxemic dogs. Am J Respir Crit Care Med. 1999 Apr;159(4 Pt 1):1186-92.

14 Radaković M, Borozan S, Djelić N, Ivanović S, Miladinović DĆ, Ristanić M, et al. Nitroso-oxidative stress, acute phase response, and cytogenetic damage in Wistar rats treated with adrenaline. Oxid Med Cell Longev. 2018 Nov;2018:1805354.

15 Karasawa T, Ikezumi Y, Suzuki T, Hasegawa H, Uchiyama M. Oxidative Imbalance in Acute Renal Failure after Exercise without Renal Hypouricemia. Nihon Shoni Jinzobyo Gakkai Zasshi. 2010;23(2):96-101.

16 Saito O, Sugase T, Saito T, Akimoto T, Inoue M, Ando Y, et al. Two cases of renal hypouricemia in which dopamine infusion produced a good recovery from exercise-induced acute kidney injury. Clin Nephrol. 2011 Aug;76(2):83-90.

17 Basile DP, Anderson MD, Sutton TA. Pathophysiology of acute kidney injury. Compr Physiol. 2012 Apr;2(2): 1303-53.

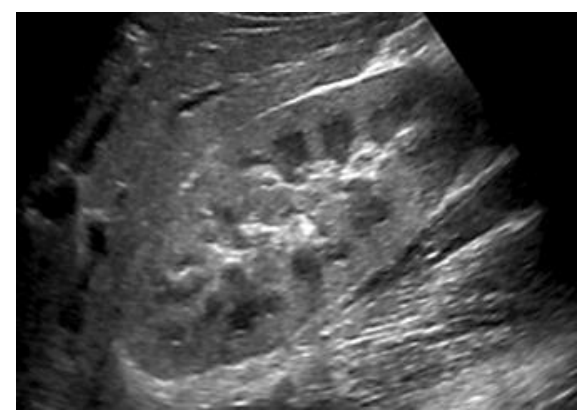

Fig. 1. Renal ultrasound showed mild kidney swelling with increased renal cortical echogenicity. Hydronephrosis and renal calcification were not observed. Renal imaging findings were similar bilaterally (left $105 \times 62 \mathrm{~mm}$, right $115 \times 63 \mathrm{~mm}$ ) 


\section{Case Reports in Nephrology and Dialysis}

Case Rep Nephrol Dial 2020;10:26-34

(c) 2020 The Author(s). Published by S. Karger AG, Basel www.karger.com/cnd

Aomura et al.: A Case of Acute Kidney Injury in a Patient with Renal Hypouricemia without Intense Exercise

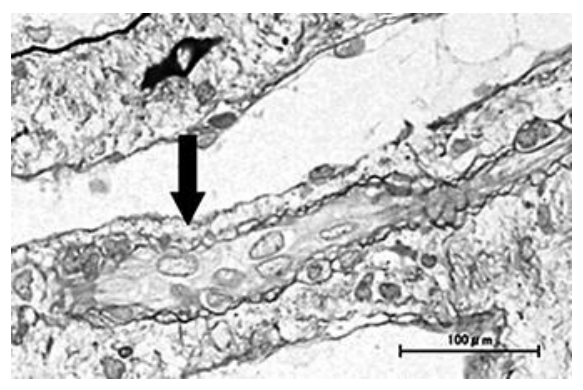

Fig. 2. Kidney biopsy specimen findings. Mild interstitial edema and vascular lumen narrowing by endothelial cell swelling (arrow) were detected (periodic acid-methenamine silver stain). No other abnormalities were found, including signs of acute tubular necrosis.

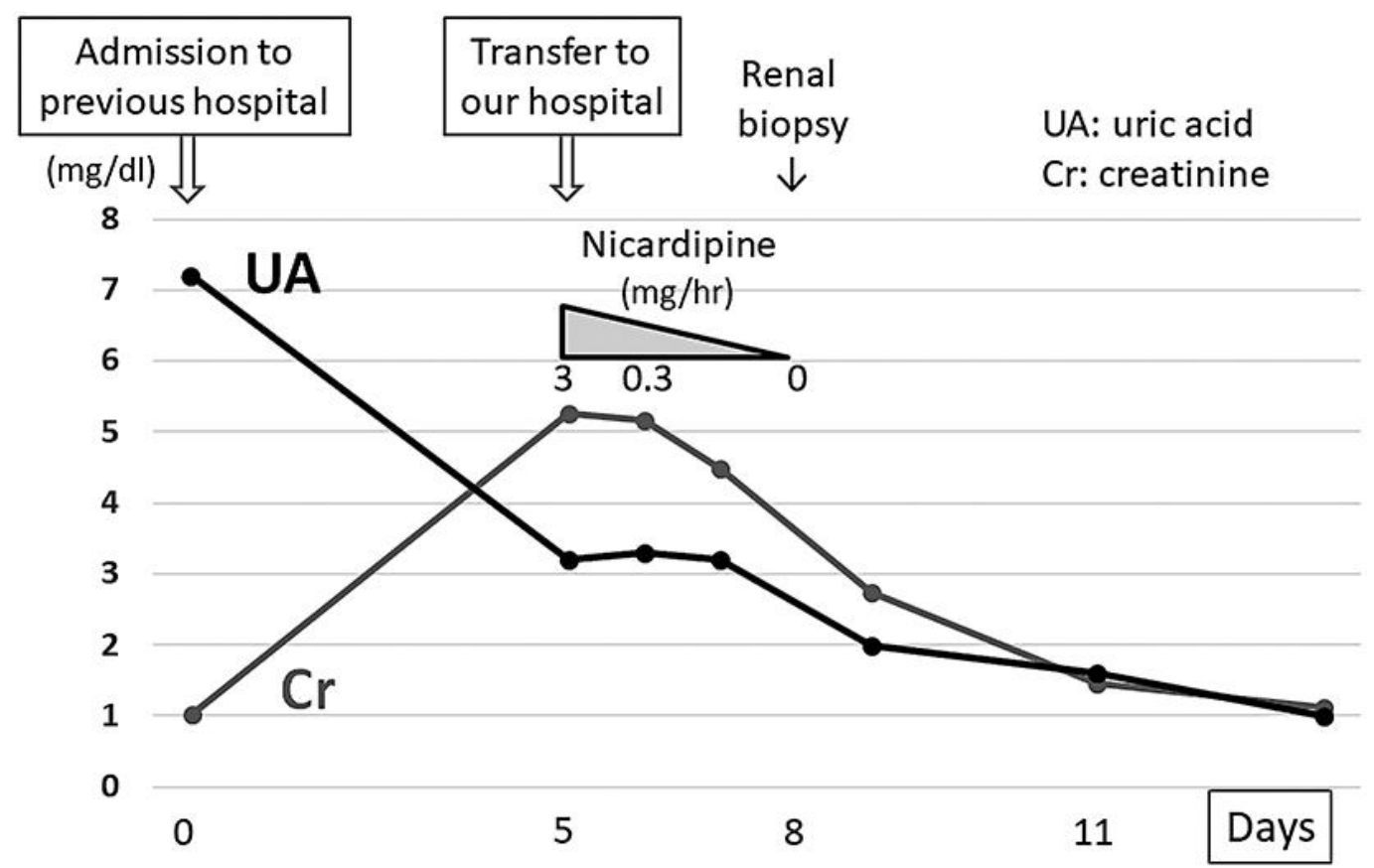

Fig. 3. Clinical course of the present case. Vasopressors that had been administered for 15 days were discontinued on admission. After transfer to our hospital, his renal function improved gradually with continuous intravenous infusion of extracellular fluids and nicardipine. The serum uric acid level decreased steadily to $1.0 \mathrm{mg} / \mathrm{dL}$ during hospitalization. 

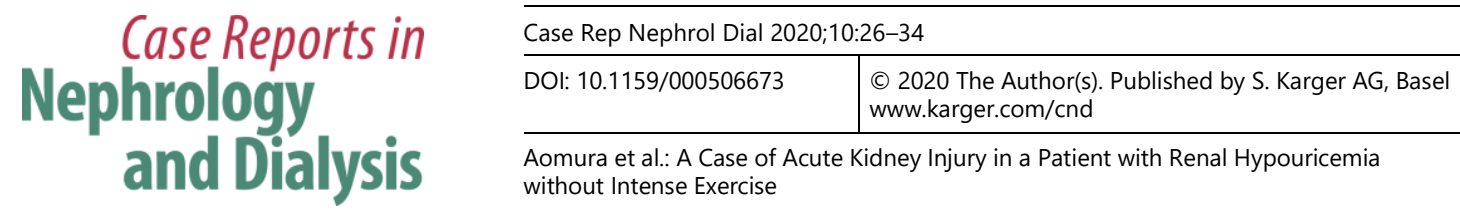

Aomura et al.: A Case of Acute Kidney Injury in a Patient with Renal Hypouricemia without Intense Exercise

Table 1. Main laboratory data on admission to our hospital

\begin{tabular}{|c|c|c|c|}
\hline \multicolumn{4}{|l|}{ Urinalysis } \\
\hline $\mathrm{pH}$ & 6.0 & Urinary chemistry & \\
\hline Specific gravity & 1.005 & Protein & $38 \mathrm{mg} / \mathrm{dL}$ \\
\hline Screening dipstick test & & & $0.66 \mathrm{~g} / \mathrm{gCr}$ \\
\hline Protein & \pm & Urea nitrogen & $234 \mathrm{mg} / \mathrm{dL}$ \\
\hline Glucose & - & Creatinine & $48.6 \mathrm{mg} / \mathrm{dL}$ \\
\hline Ketones & - & Sodium & $32 \mathrm{mEq} / \mathrm{L}$ \\
\hline Occult blood & - & Beta-2-microglobulin & $1,498 \mu \mathrm{g} / \mathrm{L}$ \\
\hline Sediment & & NAG & $3.1 \mathrm{U} / \mathrm{L}$ \\
\hline Red cells & $0 / \mathrm{HPF}$ & FENa & 2.2 \\
\hline White cells & $1-4 / \mathrm{HPF}$ & FEUA & 49.7 \\
\hline Epithelial casts & $1-9 / \mathrm{WF}$ & & \\
\hline \multicolumn{4}{|l|}{ Blood analysis } \\
\hline Complete blood count & & AST & $15 \mathrm{IU} / \mathrm{L}$ \\
\hline White blood cells & $6,370 / \mathrm{mm}^{2}$ & ALT & $4 \mathrm{IU} / \mathrm{L}$ \\
\hline Hemoglobin & $14.5 \mathrm{~g} / \mathrm{dL}$ & $\mathrm{LDH}$ & $258 \mathrm{IU} / \mathrm{L}$ \\
\hline Hematocrit & $41.6 \%$ & $\mathrm{CPK}$ & $114 \mathrm{IU} / \mathrm{L}$ \\
\hline Platelets & $19.4 \times 10^{4} / \mathrm{mm}^{2}$ & Sodium & $137 \mathrm{mEq} / \mathrm{L}$ \\
\hline Serum chemistry & & Potassium & $5.6 \mathrm{mEq} / \mathrm{L}$ \\
\hline Total protein & $7.3 \mathrm{~g} / \mathrm{dL}$ & Chloride & $104 \mathrm{mEq} / \mathrm{L}$ \\
\hline Albumin & $4.3 \mathrm{~g} / \mathrm{dL}$ & Calcium & $9.3 \mathrm{mg} / \mathrm{dL}$ \\
\hline Blood urea nitrogen & $45.1 \mathrm{mg} / \mathrm{dL}$ & Phosphate & $4.5 \mathrm{mEq} / \mathrm{L}$ \\
\hline Creatinine & $5.26 \mathrm{mg} / \mathrm{dL}$ & Magnesium & $2.3 \mathrm{mg} / \mathrm{dL}$ \\
\hline Uric acid & $3.2 \mathrm{mg} / \mathrm{dL}$ & & \\
\hline
\end{tabular}

ALT, alanine aminotransferase; AST, aspartate aminotransferase; CPK, creatine phosphokinase; FENa, fractional excretion of sodium; FEUA, fractional excretion of uric acid; HPF, high-power field; LDH, lactic dehydrogenase; NAG, N-acetyl- $\beta$-D-glucosaminidase; WF, whole field. 

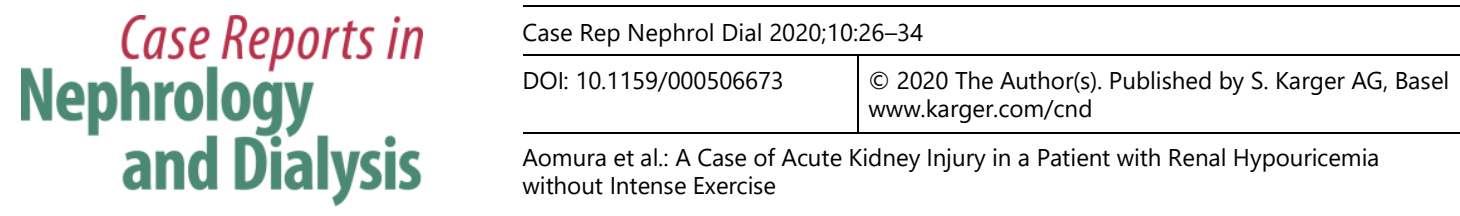

Aomura et al.: A Case of Acute Kidney Injury in a Patient with Renal Hypouricemia without Intense Exercise

Table 2. Clinical findings of current and previous reported cases of EIAKI without strenuous exercise

\begin{tabular}{|c|c|c|c|c|c|}
\hline Reference & $\begin{array}{l}\text { Patient } \\
\text { No. }\end{array}$ & $\begin{array}{l}\text { Age, } \\
\text { years }\end{array}$ & Sex & $\begin{array}{l}\text { Coincidence } \\
\text { of RHUC }\end{array}$ & Suspected trigger \\
\hline Ohta et al., & 1 & 14 & male & yes & gastroenteritis \\
\hline 2004 [2] & 2 & 30 & male & yes & unknown \\
\hline \multirow[t]{5}{*}{$\begin{array}{l}\text { Lee et al., } \\
2012[3]\end{array}$} & 3 & 33 & male & unknown & $\begin{array}{l}\text { URI and heavy alcohol } \\
\text { consumption }\end{array}$ \\
\hline & 4 & 23 & female & unknown & URI \\
\hline & 5 & 25 & male & no & URI \\
\hline & 6 & 32 & male & no & analgesics \\
\hline & 7 & 30 & male & unknown & unknown \\
\hline $\begin{array}{l}\text { Sugimoto et al., } \\
2007 \text { [4] }\end{array}$ & 8 & 49 & male & yes & coincidence of myalgia \\
\hline Current case & 9 & 15 & male & yes & vasopressor \\
\hline
\end{tabular}

EIAKI, exercise-induced acute kidney injury; RHUC, renal hypouricemia; URI, upper respiratory infection. 